\title{
УПОТРЕБЛЕНИЕ ПРЕЦЕДЕНТНЫХ ИМЁН ВО ФРАЗЕОЛОГИЧЕСКИХ ЕДИНИЦАХ КИТАЙСКОГО ЯЗЫКА
}

\section{THE USE OF PRECEDENT NAMES IN PHRASEOLOGY}

Cui Yufei

Summary: In Chinese history, there are many famous precedent names that have become a component of phraseological units. For native Chinese speakers they are part of the culture, stored in the popular consciousness. Such phraseologisms with precedent names are used in the real communication of the Chinese people, enriching the language and adding eloquence to interaction. The sources and processes of forming the meanings of such phraseological units reflect the morals, mentality and worldview of the Chinese people, they have entered the Chinese cognitive base.

Keywords: precedent names, phraseology, mentality, use, cognitive base.

\author{
Цуй Юйфэй \\ аспирант, Московский государственный университет \\ имени М.В. Ломоносова \\ victoria-yufei@mail.ru
}

Аннотация: В китайской истории есть много известных прецедентных имён, которые стали составляющей фразеологизмов. Для носителей китайского языка они представляют собой часть культуры, хранящейся в народном сознании. Такие фразеологизмы с прецедентными именами используются в реальной коммуникации на китайском языке, обогащая язык и добавляя красноречия в общении. Источники и процессы формирования значений подобных фразеологизмов отражают мораль, ментальность и мировоззрение китайского народа, они вошли в китайскую когнитивную базу.

Ключевые слова: прецедентные имена, фразеологизм, ментальность, употребление, когнитивная база.

использовать прецедентное имя.

Источником происхождения прецедентных имён могут быть как реальные исторические фигуры, так и литературные персонажи. Также существует немало исторических известных личностей, описанных в романах или в стихотворениях последующими поколениями. Практически не существуют прецедентных имён, образованных от имён современников, в той или иной степени они живут лишь «на бумаге». Постараемся показать использование прецедентных имен в текстах.

1) В качестве первого примера возьмём историю прецедентного имени Дун Ши, которое стало антонимом красавицы. История Дун Шиописана в 14-м разделе «Круговорота небес» книги «Чжуанцзы» («庄子.天运»). Дун Ши была соседкой Си Ши, которая была древней китайской красавицей. Дун Ши была некрасивой девушкой, которая жила на востоке деревни. Их имена имеют отношение к пространственным отношениям: по произношению «дун» - восток, «си» - запад).

故西施病心而颦其里， В старину красавица Си Ши изза болей в сердче была печальна.

其里之丑人见而美之, Увидала её некая Уродина и, вернувшись домой,

归亦捧心而频其里。 тоже стала хвататься за сердие и охать на виду увсех. 


\section{其里之富人见之， Однако богачи, завидев её,}

坚闭门而不出； бросались запирать ворота，

贫人见之，彗妻子而去之走。 $а$ бедняки， повстречав её, убегали прочь вместе с домочадчами.

彼知跙美，Уродина понимала только, что быть печальной красиво,

而不知將之所以美。ноне понимала, почемуэто так.

[庄周, 2005, с. 102] [Чжуанцзы, 1995, с. 121] 102]

“颦”(pín) обозначает «нахмурить брови», в данном переводе это значение отсутствует. В китайском языке имя Дун Ши в китайском языке связано с устойчивым выражением“东施效踒”: «Дун Ши подражает тому, как нахмурить брови, что обозначает“слепое подражание"» [Воропаев, 2015, с. 86]. В китайском фразеологическом словаре указан источник этого фразеологизма и его значение“比喻不根据具体条件，盲目模仿别人，效果 适得其反"汉语成语大词典, 1985, c. 263]。Это метафора означает, что безумно подражать другим - непрактично и глупо, в результате это приведёт к противоположному эффекту. Китайцы используют его, когда кто-то искусственно подражает другим и это выглядит смешно. Например，"我这是向您学的，可是学得不好，可谓东施 效频。": «Этому я у вас научился, но видно ты плохо научился, это можно назвать смехотворным обезьянничаньем» [Воропаев, 2015, с. 87].

2) Второй пример -“叶公1 好 ${ }^{2}$ 龙” “Егун обожает дракона». Здесь необходимо отметить, что в Китае «дракон» считается легендарным мифическим животным, символизирующим счастье, силу и власть. Речь идёт о том, что Егун обожает дракона, весь его дом украшен изображениями дракона, они повсюду: на стенах, на одежде. А настоящий дракон, живущий в небесах, узнав об этом, прилетел к Егуну домой. При виде настоящего дракона Егун перепугался до дрожи и поспешил спрятаться [Китайский язык, 2006, с. 57-58]. В большом словаре китайских фразеологизмов указано следующее значение:"比喻表面爱好某事物，真正面临某事物 时，反而畏惧" [汉语成语大词典, 1985， c. 1368], метафо- ра, обозначающая, что «человек любит что-то, но боится, когда на самом деле сталкивается с чем-то». Эту идиому в народе очень широко используют с отрицательным значением в общении. Прецедентное имя"叶公"стал символом поддельного любителя чего-нибудь. Напримep: 喜爱一件事不能只是叶公好龙，要真正付出自己的 努力 [10]。《Если любишь что-нибудь, то не следует вести себя, как Е-гун, нужно быть искренним в своих чувствах».

3) Рассмотрим третий пример “卧薪尝胆”- букв. «лежать на хворосте и пробовать на вкус желчь» [Воропаев, 2015, с. 277]. Эта идиома отличается от первых двух примеров тем, что прецедентное имя не присутствует в ней непосредственно, есть только действия от этого имени. В основе возникновения имени лежит история о Гоу Цзяне, правителе царства Юэ. В конце эпохи Вёсен и Осеней (6-5 вв. до н.э.) царство У (правителя, которого звали Фу Чай) завоевало царство Юэ. Гоу Цзянь лежал на хворосте и пробовал на вкус желчь, чтобы не забыть о чувстве ненависти к Фу Чаю. В словарной статье приведено следующее значение“形容刻苦自励，奋发图强，或立志为国 家报仇雪耻" [汉语成语大词典, 1985, с. 1217] : - трудолюбие, самонадеянность, или стремление мстить за оскорбление (завоевал его царство Юэ). Сейчас фраза используется значении «терпевший трудности ради великой будущей цели». Например: 中国足球要想冲出亚洲，必 须卧薪尝胆，刻苦训练 [11]。《Для того, чтобы китайский футбол вырвался из Азии, он должен лежать на хворосте и пробовать на вкус желчи и тренироваться с усердием». А Гоу Цзянь стал примером тех усилий, которые нужно приложить для достижения своей цели.

Таким образом, мы разобрали три примера китайских фразеологизмов, в которых используются прецедентные имена, их источники и значения, их употребление, и то, какое влияние они оказывают на китайский народ. Изучение китайских фразеологизмов чрезвычайно полезно с точки зрения понимания китайской культуры, и многие из них тесно связаны с прецедентными именами и их действиями. Для иностранцев и тех, для кого китайский язык является иностранным, изучение употребления фразеологизмов, касающихся прецедентных имён, играет важную роль в осмыслении фразообразовательного значения данных связанных языковых средств.

\section{ЛИТЕРАТУРА}

1. Баранова 3.И. Чэнъюй как разряд фразеологизмов китайского языка. Автореф. дис. канд. филол. наук. АН СССР, Ин-т востоковедения М.: 1969. 24 с.

2. Войцехович, И.В, Практическая фразеология современного китайского языка. Учебник. М.: АСТ: Восток-Запад, 2007. 509 с.

3. Воропаев Н.Н. Китай: имена на все времена: Прецедентные персонажи. М.: ВКН, 2015. 384с.

“叶公”в настоящее время произносится как «Е-гун», ранее был принят вариант - «Шэгун».

2 Иероглиф“好" имеет 2 важных значения: 1) используется в качестве прилагательного, произносится третьим тоном, обозначает «хорошо»: 2) используется в качестве глагола, произносится четвёртым тоном. Здесь употребляется как глагол в значении «любить, нравиться». 
4. Кулинич М.А. Теория и практика межкультурной коммуникации: учебное пособие. М.: ФИИНТА: наука, 2017. 248с.

5. Китайский язык. 50 классических бесен. Читаем параллельно на китайском и русском языках. М.: Восточная книга, 2006. 128 с.

6. Манерко Л.А., Сложноструктурное субстантивное словосочетание: когнитивно-дискурсивный аспект (на материале технической литературы современного английского языка): дис. ... д-ра филол. наук. М.: МГУ имени М.В. Ломоносова, 2000. 425 с.

7. Чжуан-цзы (перевод В.В. Малявина) М.: Мысль, 1995. 332 с.

8. 庄周. 庄子. c. 39-188 // 老子，庄子，列子. 吉林 : 时代文艺出版社 ， 2005. 308с. (Чжуан Чжоу. Чжуанцзы. // Лаоцзы, Чжуанцзы, Лэцзы. Цзи Линь: изд-во в эпохе литературы и искусства).

9. 汉语成语大词典.湖北大学语言研究室.河南人民出版社，1985. 1592 с. (Большой словарь китайских фразеологизмов. Лингвистическая кафедра Университета Хубэй. Хэнань: Народное изд-во Хэнань).

10. Примеры составить предложений фразеологизмом“叶公好龙”. URL: https://zaojv.com/4293472.html (дата обращения 20. 05. 2020).

11. Примеры составить предложений фразеологизмом“卧薪尝胆”. URL: https://chengyuzaoju.zou.la/wra2.html (дата 0бращения 20. 05. 2020).

(c) Цуй Юйфэй (victoria-yufei@mail.ru)

Журнал «Современная наука: актуальные проблемы теории и практики»

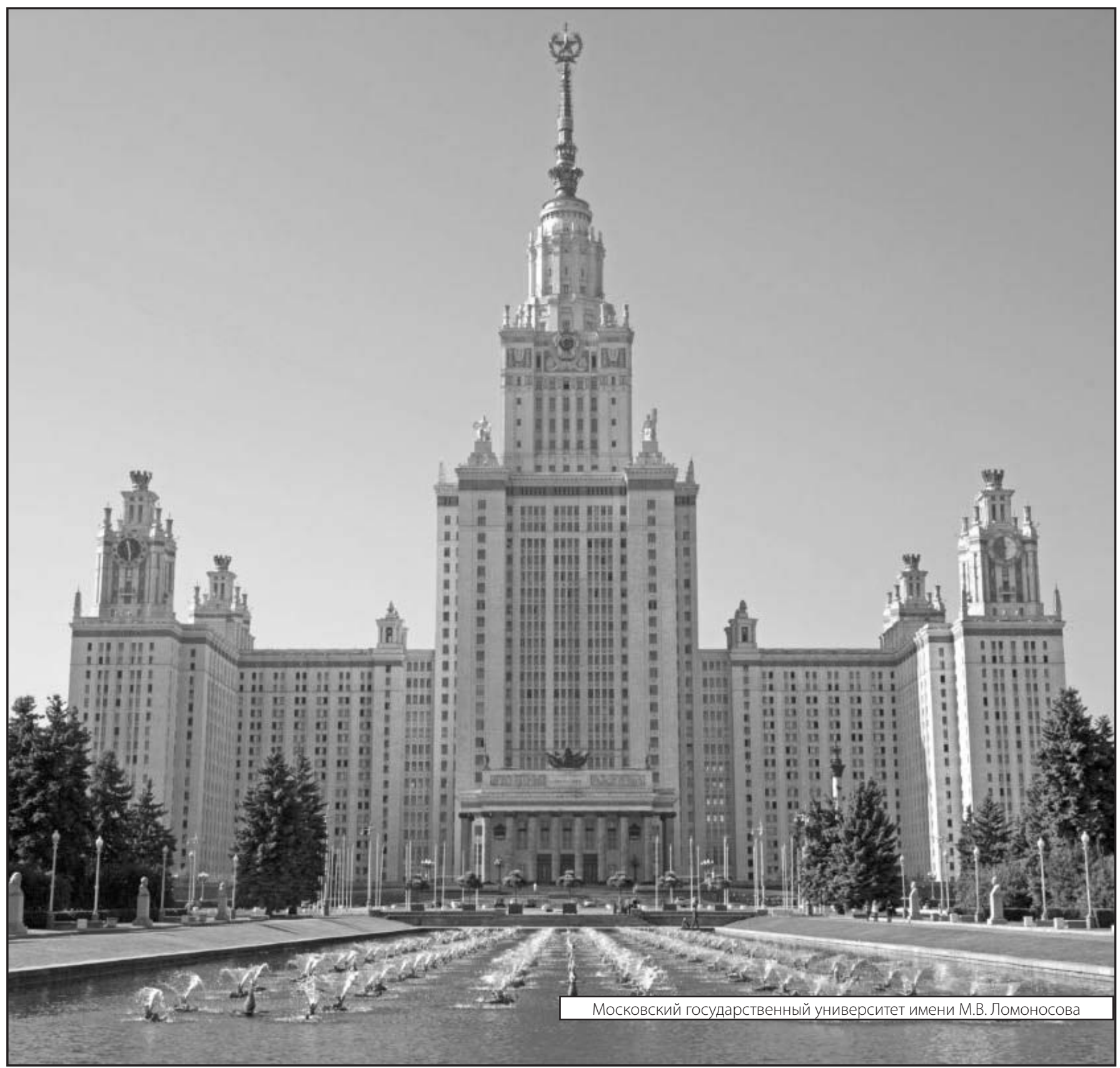

